\title{
Preface to Special Issue on Electrocatalysis Transformation
}

Human society is currently facing the problems of the depletion of fossil energy and severe environment pollution. The utilization of renewable energy, such as wind energy, solar energy, tide energy, etc. now forms more of the modern energy structure. Therefore, their conversion and storage technology including the use of fuel cells, rechargeable batteries, and waste-to-energy $\left(\mathrm{CO}_{2}\right.$ reduction) technology are of significance. Bringing out the full potential of these power sources will require innovations in the catalytic process and optimization of the catalytic features in the devices - improving not only the compositions but also the microstructures of the catalytic materials to provide a highly effective conversion of energy between its chemical and electrical forms.

The fuel cell is an ideal device to convert the chemical energy in fuels into electricity. The fuels include hydrogen, methanol, formic acid and other small organic molecules, while $\mathrm{O}_{2}$ or air is the oxidant. Fuel cells can produce electricity continuously for as long as the fuel is supplied, and they are already on the edge of mass application: the commercialization of fuel cell vehicles (FCVs) has already been initiated by world's largest automobile companies including Toyota, Honda, and Hyundai. However, a huge price drop is required for FCVs to compete with cars based on the internal combustion engine.

In a rechargeable battery, the chemicals in the battery react to generate an electromotive force. The lithium-air battery (Li-Air) is a metal-air battery with a chemistry that uses the oxidation of lithium at the anode and reduction of oxygen at the cathode to get a current flow. A specific energy of $\sim 1.7 \mathrm{kWh} / \mathrm{kg}$ at the cell level has been developed for the Li-Air battery, which is sufficient for an electric vehicle to run $500 \mathrm{~km}$ on a single charge.

For sustainable energy, the efficient use of wastes, including $\mathrm{CO}_{2}$ and wastewater, is also important, and which should be brought to the forefront of research.

Electrocatalysis is the central issue in the above clean energy technologies. The key materials include the catalysts for the anode and cathode, where the oxidation reaction of fuels and metals at the anode and the reduction reaction of oxygen and $\mathrm{CO}_{2}$ at the cathode determine the performance. The high price and scarce reserve on the Earth of the platinum group metals are a major obstacle in the commercialization of fuel cells, although they are presently used because they are unique in their high activity and stability. Hence, the price reduction of electrocatalysts by exploring non-metal catalysts without sacrificing the catalytic performance is urgently required. For the metal-air battery, the development of electrocatalysts and battery systems with high performance and high cycling stability is the ultimate target.

This special issue of Chinese Journal of Catalysis contains 23 articles that focused on the use of electrocatalysis in renewable energy technology. All articles were contributed by eminent scientists who worked at the front line of the electrocatalysis field and have rich experiences in both fundamental studies and applications. We hope that this issue will also provide a valuable reference for researchers in related areas, thus stimulating more efforts to develop advanced catalytic materials and investigating the mechanisms of the reactions. We thank all the outstanding authors and reviewers who contributed to this special issue. It is their expertise, enthusiasm, and hard work that resulted in this high quality issue. We also want to acknowledge the editorial and production staff for the time and effort they have devoted.

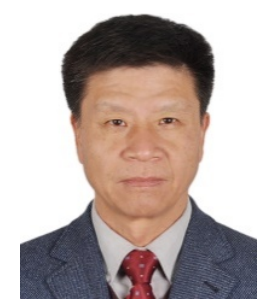

Prof. Shigang Sun (Guest Editor)

Department of Chemistry,

Xiamen University

E-mail: sgsun@xmu.edu.cn

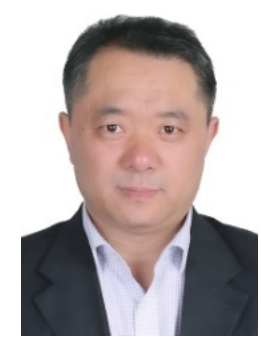

